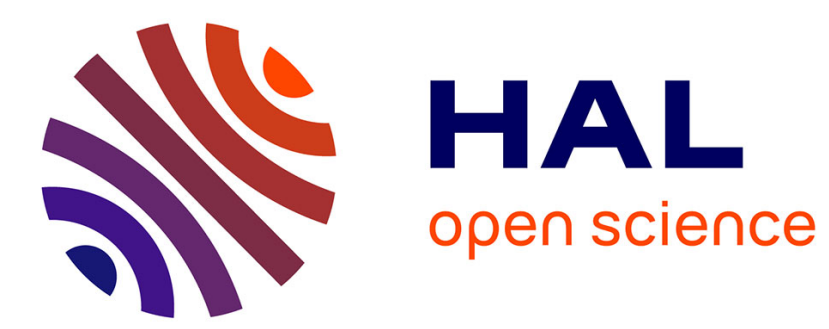

\title{
A Relational Approach to Materiality and Organizing: The Case of a Creative Idea
}

Thomas Martine, François Cooren

\section{To cite this version:}

Thomas Martine, François Cooren. A Relational Approach to Materiality and Organizing: The Case of a Creative Idea. Beyond Interpretivism? New Encounters with Technology and Organization, 2016, 978-3-319-49732-7. 10.1007/978-3-319-49733-4_9 . hal-01651223

\section{HAL Id: hal-01651223 \\ https://hal-audencia.archives-ouvertes.fr/hal-01651223}

Submitted on 30 Nov 2017

HAL is a multi-disciplinary open access archive for the deposit and dissemination of scientific research documents, whether they are published or not. The documents may come from teaching and research institutions in France or abroad, or from public or private research centers.
L'archive ouverte pluridisciplinaire HAL, est destinée au dépôt et à la diffusion de documents scientifiques de niveau recherche, publiés ou non, émanant des établissements d'enseignement et de recherche français ou étrangers, des laboratoires publics ou privés. 


\title{
A Relational Approach to Materiality and Organizing: The Case of a Creative Idea
}

\author{
Thomas Martine ${ }^{(\sqrt{\star x})}$ and François Cooren \\ Université de Montréal, Montreal, Canada \\ \{thomas.martine, f.cooren\}@umontreal.ca
}

\begin{abstract}
In this paper, we propose to go beyond the notion of entanglement that has been proposed in recent years to fill the so-called gap between "the social" and "the material", especially in organizational studies. While this notion rightly invites us to reconsider the way we traditionally approach the question of materiality and organizing, we believe that its formulation tends to implicitly reproduce the gap it claims to fill. In contrast, we propose a view according to which sociality and materiality should, in fact, be considered aspects of everything that comes to be and exist. Throughout the analysis of an episode taken from fieldwork devoted to creative teams, we show that things as abstract as ideas, for instance, in order to emerge, exist, and continue to exist, have to materialize themselves in various identifiable beings. While the sociality of an idea is identified through the various relations that make it what it is, we show that its materiality comes from what precisely materializes these relations.
\end{abstract}

Keywords: Relational ontology $\cdot$ Aspectuality $\cdot$ Communication $\cdot$ Materiality $\cdot$ Organization $\cdot$ Sociomateriality

\section{Introduction}

In keeping with the existent literature on sociomateriality (especially [1]), we refute the distinction between, on one side, a material world, and on the other side, a social world. However, we believe that the concept of entanglement, as proposed by Barad [2] and taken up by Orlikowski [3], unfortunately implies the idea of things - for instance, meaning and matter [2] or sociality and materiality [4] - being wrapped or twisted together, which implies that their ontological distinction is still maintained even if their entanglement indeed makes this distinction difficult to make. This language problem has been mentioned by Orlikowski herself [4], but also by Kautz and Jensen [5] as well as Cecez-Kecmanovic [6].

With the notion of aspectuality, which we propose and explain, we show that materiality and relationality (a term we prefer, as we will explain, to sociality) should, in fact, be considered aspects of everything that exists, whether we are talking about emotions, ideas, discourses, practices, institutions, computers or rocks. If this position is compatible with the relational ontology defended by Barad [2] and Orlikowski and Scott [4], 
we believe that it allows us to specify the nature of this ontology by clarifying what we mean by matter and what we mean by relation.

Having established our position, we then examine what it implies for the CCO (Communication as Constitutive of Organization) approach [7-9] in its various forms [10], that is, the view according to which organizations and, more generally, reality itself [11], should be considered as communicatively constituted. As we will show, the CCO approach should not only be considered compatible with this material turn, but allows tackling the questions of materiality and relationality in a manner that is at once practical, embodied, and dynamic.

We then illustrate our approach by analysing the pitch of an idea during a creative event called Museomix. In our analysis, we identify the various beings (among them a stage, people, words, gestures, paintings, a wooden board, languages, expectations, etc.) through which this idea materializes. In other words, we show how this idea emerges when these various beings start relating to one another.

\section{Sociomateriality: Weak and Strong Versions}

For the last ten years, organization studies have taken what has come to be known as a material turn [12-14], a turn that had already started in other areas of the social sciences and humanities, from gender studies [15], to science and technology studies [16, 17], and to Deleuze's [18] and Foucault's philosophies [19]. This turn, which centred on the key notion of sociomateriality [3], can be roughly defined according to two main research programs, which defend weaker and stronger versions of sociomateriality [20].

According to the weaker version, rethinking materiality essentially means acknowledging that objects, bodies, technologies, artifacts, architectural elements, and apparatuses of all sorts play a full part in the existence and reproduction of routines and organizational processes. This movement, mainly represented by Paul Leonardi's [21, 22] seminal work, therefore amounts to recognizing that we cannot reduce organizational phenomena to processes of sensemaking, as Karl Weick [23, 24] or Linda Putnam and Michael Pacanowsky [25], in their time, invited us to do. We also have to acknowledge the differences that artifacts, technologies, and apparatuses make in these routines and processes, what Leonardi identifies, echoing Pickering [26], as a form of material agency.

Leonardi's $[21,22]$ approach to sociomateriality indeed consists of showing that the two elementary building blocks of organizations and technologies are, on one side, human agency, which is goal oriented and therefore marked by a form of intentionality, and, on the other side, material agency, which is almost always identified with what technologies do and is devoid of intentionality. These two agencies are presented as articulated according to two main sociomaterial imbrications - human $\rightarrow$ material and material $\rightarrow$ human - that characterize the evolution of any technological implementation and, more broadly, of any organization.

Although this approach explicitly "denies any separation of technology from organizing" [22] (p. 41), the notion of imbrication "allows for maintaining the distinction 
between social and material agencies with respect to intentionality while still recognizing their synergestic interaction" [22] (p. 46). According to this version of sociomateriality:

as people attempt to reconcile their own goals with a technology's materiality they actively construct perceptual affordances and constraints. Depending on whether they perceive that a technology affords or constrains their ability to achieve their goals they make choices about how they will imbricate social and material agencies [22] (p. 50).

The connection between the social and the material is therefore essentially a matter of imbrications, which are very nicely analysed by Leonardi [21, 22] in his ethnography of a case of computer simulation technologies for automotive design. It is, however, noteworthy that in this case, materiality is essentially identified with technology, that is, whenever this author talks about material agency, his illustrations tend to always take the form of technological agency; what differences technologies make in specific situations. In contrast, whenever he talks about social agencies, he actually implies human agencies, which, for instance, take the form of specific routines, conducts, and conversations.

Leonardi's approach to sociomateriality thus is that the elementary building blocks of organizations and technologies are human/social agency and material/technological agency. We believe that this approach (as fruitful and interesting as it is) presents two limitations:

1. Human/social agency seems to exist independently from materiality, while it may be argued that it is made up of material elements.

2. Once something during fieldwork has been labelled an elementary building block of phenomenon (either human/social or material/technological agency), it seems that we cannot further decompose this thing, thus preventing us from gaining potential new insights in the phenomenon under study.

In contrast with this approach, there exists what we could call a stronger version of the sociomaterial thesis, where the material turn goes beyond the simple recognition that (a) we live in a material/technological world to which we, the humans, need to adapt our goals and that (b) this world makes a difference in the way we organize ourselves, especially in the case of technological implementations. According to this other version, mainly represented by Barad's [2] as well as Orlikowski and Scott's [1, 4] work, there is no cut, break, or bifurcation between materiality and sociality, which ultimately means that the distinction between social and material agencies cannot be maintained.

In contrast with Leonardi's notion of imbrication, Barad [2] thus proposes the notion of entanglement, a notion taken up by Orlikowski [3, 4], that is supposed to mark the constitutive entanglement of meaning and matter. One of the reasons that make this notion difficult to present is that it was sometimes misrepresented by the very authors who adopted it. Indeed, in their first articles on sociomateriality, Orlikowski and Scott $[3,4]$ tended to present this "constitutive entanglement" as meaning that humans and non-humans (in particular technologies) could not be ontologically separated, an idea that was then harshly criticized notably by Faulkner and Runde [27], Mutch [28], and Leonardi [29]. 
As these latter authors argued, while most people would likely agree that it is impossible to have, for instance, meaning or humans without any form of matter involved, it seems, however, a lot more difficult to agree that it is impossible to have matter without meaning or humans. Does this mean that when the moon is not connected to some sort of discourse or meaning it does not exist? Is it to say that people produce the entire world when they speak about it? This idea surely sounds like a caricature of constructivism.

However, this is not what Barad [2] and Orlikowski, in her subsequent articles [1], mean because they develop what Barad calls a "posthumanist" approach to discourse and meaning. For them, discourse and meaning do not necessarily involve humans or human action. When a tree falls, this event is already in itself meaningful and discursive (i.e. even if no human is there to see, hear, and speak about it) in the sense that the tree and the ground communicate their existence to each other, for instance through the vibrations that run through them on impact.

Thus, through the change that they undergo, the tree and the ground become related and meaningful to each other. The idea, in other words, is that the elements of the world somehow "communicate" to one another in their own special way; a position that we also find in the work of the anthropologist Eduardo Kohn [30] when he shows how forests can be said to think. Now, what are Barad and Orlikowski trying to accomplish with this posthumanist understanding of discourse and meaning? Their point is to show that contrary to the way it is usually defined, matter is not something that sits still. Regardless of how much a given piece of matter appears to be stable, its stability is always the result of a particular configuration of things; meaning that if this configuration is not maintained, the stability disappears.

Put another way, there is nothing in this world that inherently possesses its properties. Every being, entity, or phenomenon acquires its properties by relating to other beings, entities, or phenomena (an idea we also find in Latour [31, 32], Law [33], and Pickering [26]). This relational ontology [34] has an interesting epistemological consequence: it means that any being, entity, or phenomenon - regardless of how elementary or solid it might look - can theoretically be broken down into a web of relations between various beings, entities, or phenomena. This approach, it seems, allows overcoming the theoretical and empirical limits related to the division of the (organizational and technological) world into elementary units of human and material agencies, as proposed by Leonardi [21, 22].

However, we cannot help but notice the high "cost" of this solution. There are two issues that make this solution particularly difficult (or "costly") to communicate and work with. The first issue, as already mentioned, is that Barad's and Orlikowski's approaches rely on a posthumanist definition of "discourse" and "meaning", which tends to contradict the common use of these terms (that are usually associated with humanrelated phenomena). This approach can thus be easily mistaken for a form of radical constructionism. The second issue concerns the ambiguity of expressions such as "the constitutive entanglement of meaning and matter" or expressions such as "material discursive practices", which both authors keep using in their respective work (see also [4-6] on this language problem).

By definition, "entanglements" involve elements that, although closely interlocked, can be ontologically separated. It follows that the very word "entanglement" tends to 
defy the inseparability that Barad and Orlikowski have in mind when speaking about the constitutive (or ontological) entanglement of meaning and matter. A similar remark can be made about the expression "material discursive practices" where the juxtaposition of the adjectives "material" and "discursive" invites the idea that there might be "material practices" on one side and "discursive ones" on the other and that they sometimes come together. Here again, the words seem to resist or defy the idea.

Although the notion of entanglement should definitely be considered an improvement, as it explicitly invites us to reject the separateness of the material and social worlds (see especially [1]), we believe that it tends to be misleading as it invites us to still take for granted the existence of two things, however entangled/twisted/wrapped together they might be at the ontological or constitutive level. Entangling indeed means to "cause to become twisted together with or caught in" (Oxford Dictionary), which means that the notion of entanglement presupposes, by definition, the existence of worlds or things - for lack of better words - that are indeed twisted or wrapped together.

Even if Orlikowski and Scott's [1] most recent analyses cannot be accused of reproducing this implicit divide, the first formulations that Orlikowski [3] proposed to conceptualize the notion of entanglement - which happens to be the one that the literature retains and comments on [20] - tends to be problematic. This is, for instance, what happens when she writes, "the social and the material are considered to be inextricably related - there is no social that is not also material, and no material that is not also social" [3] (p. 1437), a formulation that implies that there is something called "the social" and something called "the material" that are both entangled at the constitutive/ontological level.

\section{Sociomateriality: An Aspectual Version}

In contrast with this formulation, we believe that we need to go one step further by recognizing that speaking about "the social" on the one hand, and "the material" on the other hand, does not make a lot of sense; even if we consider the entangled or imbricated aspects of these two worlds [35]. In keeping with Orlikowski and Scott [1], we certainly claim that there are no such things as a material world - the world of tables, rocks, technologies, buildings, etc. - on one side, and a social world - the world of words, interactions meanings, cultures, emotions, and ideologies - on the other. Words, interactions, meanings, cultures, emotions, and ideologies are always already material, while rocks, tables, technologies, and buildings are always already social (in a posthumanistic sense).

According to this third version of sociomateriality, sociality and materiality should be considered two different and intractable aspects of everything that comes to exist and be [36]. By focusing on the material aspect of something or someone, we highlight what sustains its existence. Indeed, matter comes from the Latin word materia, which means "the substance from which something is made", where substance means "what stands [stare] under [sub]" something or someone [37] (p. 301). This explains why something as abstract as an emotion, an idea, or even an intuition has to materialize itself in one way or another in order to exist [38]. 
It does not mean that all entities have the same degree or level of materiality (some entities - e.g. rocks for instance - can indeed appear to be more material or concrete than others - e.g. an idea, when it crosses somebody's mind). However, it means that materiality is an intractable aspect of everything that exists and that this notion should therefore be understood relationally. In other words, the materiality of something or someone expresses the relation of sustainability or supportability that specific elements have vis-à-vis the existence of this thing or person. This way of defining materiality relationally thus allows avoiding the pitfall of looking for matter in an absolute way. Matter is always as such in relation to what it materializes.

In contrast, focusing on the social aspect of something or someone means that we focus on the relations it/he/she is literally made of, that is, the relations that connect it/ him/her with other beings. As Latour [31] reminds us, the term "social" indeed comes etymologically from the Latin sequor, which means "to follow" - a word that also gave the Latin secta, which means a line of conduct, way of life, or principle, and is the root of the English word "sect" [36]. Speaking about the social aspect of something or someone thus amounts to referring to what relates this thing or person to other beings. For human beings, this would be, for instance, the principles, lines of conduct, or ways of life they tend to follow collectively, while for an emotion, it would be what triggered or caused it (an event, for instance), but also what this emotion is itself triggering or causing (a reaction, for instance).

Sociality and materiality are indeed related to each other, but these two notions invite us to analyse someone or something under two different aspects: if we focus on the materiality of a given being, we also focus on the other beings that compose its existence. For instance, an organization is literally made of its spokespersons, employees, website, contracts, operations, buildings, products, discourses, knowledges, atmospheres, cultures, spirits, customers, stakeholders, reputation, etc., which can all be defined as its properties [39-41], knowing, of course, that each of these element is itself/herself/ himself made of other elements that compose its/his/her existence. The notion of materiality thus invites us to focus on what sustains the existence of anything or anyone, even when this thing or person appears to be outside of this thing or person (this is the case, for instance, with customers or stakeholders of an organization).

If, in contrast, we focus on the sociality of a given being, we will then concentrate on the relationships that compose its/his/her existence, that is, the fact that its/his/her components or properties are themselves related to one another (they form a configuration). In other words, this being is itself/himself/herself caught in a web of relations with other beings. For instance, if an organization is made of its spokespersons, employees, website, contracts, operations, buildings, products, discourses, knowledges, atmospheres, cultures, spirits, customers, stakeholders, reputation, etc., it is also because these elements are themselves related to one another.

As an illustration, we could point out that if an employee can be said to materialize an organization, it is because, among other things, she signed a contract with this organization, she has been authorized to speak on its behalf, she supposedly knows how to speak about its products, and she talks to customers on the phone (for whom she embodies the company at this moment); that is, because she relates this organization to various beings or entities. If the customers feel that their concerns have been addressed, 
they will possibly come out of this conversation with a good impression of this company, an impression that will itself participate in its constitution/materialization. This customer might then speak favourably about this organization to relatives, friends, and acquaintances, who will themselves participate in its reputation.

The representatives an organization has, the way it speaks through them to customers, the impression it leaves to these very costumers, the reputation it is able to build through these exchanges, and the customers it is able to keep through these experiences can all be considered properties of this organization. However, these properties, which materialize the organization, are, as we see, relational. That is, they depend on the relations that come to establish what constitutes the organization. This is why Derrida [42] notes that any property is, to some extent, improper, precisely because it cannot be absolute: it depends on a relation in order to exist, what Latour [32] would also call a sort of "plug in".

The social and material aspects of something or someone are therefore inseparable, not because they are entangled at the constitutive level, but because they represent $t w o$ ways by which something or someone gives itself/himself/herself to be experienced, which is what we mean by "aspect". An organization materializes itself through this employee and her discourse (two of its properties), but also through the way it is experienced by the customer as well as through the reputation it will develop over time (two other properties). In contrast, the relationality (or sociality) of this organization is precisely expressed by the preposition "through", which marks the network of relations this organization needs to go through in order to express itself.

As we see, any materialization (a spokesperson, a discourse, a customer, a stakeholder) of a given being (an organization) is always already a relation between this being and other beings (a spokesperson speaking to a customer, for instance). Conversely, any relation (between an organization and its customers, for instance) is always already a materialization of a particular being (an employee speaking on its behalf to a customer, for instance). In other words, and this point is crucial in our demonstration, any being always constitutes itself/himself/herself a relation between other beings, which also means that any relation is material, that is, it has to materialize itself in something or someone.

Speaking about the sociality and materiality of something or someone does not amount to speaking about the same aspect, which means that these two terms are not, strictly speaking, synonymous. While the sociality of something or someone insists on the relations/configurations that compose its existence (whether internally or externally, knowing that the distinction between what is inside and outside can, of course, itself be problematized), the question of materiality insists on the various elements that can be identified as participating in these relations/configurations, knowing that these elements can themselves be seen as the materialization of relations.

For instance, an organization both materializes and socializes/relates itself through an employee talking on its behalf to a customer. However, its materialization will be expressed through the employee, what she is saying, and the impression the customer will come up with based on this experience (among many other things), while its socialization will be expressed through the relations that compose these materializations: a customer talking on behalf of the organization, what she is saying on its behalf, or what 
the customer retains from this conversation (good or bad impressions). Any relation is therefore made of something or someone (it has to materialize itself in something or someone), and any materialization itself consists of relations that make it possible. The material and social aspects of something are thus somewhat unique in the sense that, although irreducibly different one from the other, they cannot present themselves one without the other.

To put it another way, although the notions of sociality and materiality define and constitute each other in our sociomaterial approach (in this respect it is no different from Orlikowski and Scott's [1]), the particular backgrounds or histories that characterize each of these notions never entirely disappear (this is where our approach perhaps departs from Orlikowski and Scott's [1]). They remain present in our sociomaterial (re)definition of materiality and sociality (in the sense that one is necessary for the definition of the other) and they are always likely to make a difference in our analyses, in the sense that the vocabulary related to matter (materialization, substance, etc.) will tend to direct our attention to what supports or constitutes given beings while the vocabulary related to relations (connections, networks, etc.) will tend to direct our attention to what flows or circulates between and through them.

We believe that our job, as sociomateriality analysts, is to empirically show that whether we use one or the other of these vocabularies, we end up describing the same beings or phenomena. While we do not have to systematically do this in our analyses (in the sense that we do not necessarily have to conduct our analyses by first using one vocabulary and then again using the other), we can regularly signal the possibility of using both vocabularies, either by mixing them (e.g. by saying that something "materializes through" something else) or by juxtaposing them (e.g. by saying that something "materializes in, that is, flows through" something else).

\section{Communication as Constitutive of Organization}

Given the role questions of sociomateriality have played for the past ten years in the development of the CCO literature [7-9, 38] in its various forms [10, 43], we now propose to explore to what extent this aspectual conception of sociomateriality can be deemed compatible with the idea of organizing and organization as being communicatively constituted [44]. At first sight, one could think that the material turn (in its three versions) disqualifies these constitutive approaches to the extent that the latter, by putting the emphasis on communication in organizational processes, would be ill equipped to account for questions of materiality.

We would like to show that these constitutive approaches - in particular those associated with the so-called Montreal school [9, 11,41,43, 45-48] - are not only compatible with this material turn, but that they allow tackling the aspectual approach to sociomateriality we just introduced in a manner that is at once practical, embodied, and dynamic. To this end, we propose to follow the aspectual view by taking as our starting point the etymology of the word "materiality" to show that mentioning the materiality of something (or someone) always amounts to showing that this thing (or person) is made, 
constituted, or composed of elements/properties that can be experienced as related to each other.

From a CCO perspective, focusing on the communicative dimension of organizations aims to show that organizations are embodied, materialized, and incorporated in various beings whose effects can be analysed (this thus amounts to focusing on the material aspect of any organizational form). It also means that our analyses should not only focus on what these beings do but also on what they express, translate, or reveal (that is, on what passes through them), which expresses their relational character. In other words, we should conceive of them not only as actors but also as passers [35]. To study communication processes therefore amounts to analysing these passing or relational effects through which a given being (a human being, a technology, an architectural element, a document, etc.) expresses, translates, or reveals other beings, thus becoming their spokesperson, representative, translator, or materializer.

If we turn to the study of organizational interactions, we notice, for instance, that words, gestures, glances, and intonations are always the expression of a true polyphony that Bakhtin $[49,50]$ had already outlined [51], but this should be extended to artifacts, emotions, cultures, and ideologies (among other things). Therefore, to analyse communication is not to bracket the material world precisely because it involves resisting the temptation to singularize this world by separating it from the world of speech, for instance. Materiality should rather be conceived of as an irreducible aspect of everything that is, including speech and any communication act in general.

This is why there is not, on one side, a material world (the one of chairs, computers, walls, etc.) and, on the other, an immaterial/social world (the one of thoughts, emotions, discourse, speech, cultures, ideas, etc.). On the contrary, if something (or someone) exists, it is always because it materializes itself in one way or another, whether through the form of a website [1, 11, 36], a spokesperson [40], a number [52], a look [41], etc. through which a relation is established. Materiality and immateriality should thus be conceived of relationally; that is, in terms of degrees. Things and beings will always more or less materialize in a given situation, through a discussion, an experience, or a feeling (among other things).

Advocating a constitutive approach to communication therefore involves going back to the very definition of a communicative act, namely the act through which a being $\mathrm{A}$ enters in relation with a being $\mathrm{B}$ through a being $\mathrm{C}$, a triadicity that Charles Sanders Peirce [53] had noticed and that can be applied to any communicative phenomenon, whether we refer to two rooms communicating (through a doorway), machines interacting (through channels and data), or people conversing (through intonations, gestures, looks, and words). Most importantly, it is to recognize that A and B, identified as the origins and recipients of these communicative acts, are also always already intermediaries themselves, in other words, potential beings C', through which other beings A' enter in relation with other beings B'.

Speaking in terms of communication rather than in terms of discourse and meaning thus allows us to highlight the relational nature of our world without resorting to concepts that have been traditionally associated with a human-centred perspective. It does not mean that discourse has to be banned from our vocabulary; it simply means that discourse is just one way through which communication happens [46]. Two rooms 
do not converse with each other, but they might indeed communicate. The same thing could be said of the tree and ground we talked about earlier.

Studying the organizing property of communication therefore amounts to showing how various beings articulate themselves (in both senses of the word: enunciating and assembling) so that they become the intermediaries, materializers, or media of one another, and that the ensuing collective action becomes that of a collective body. As a result, we also find the etymology of the term "to organize", which comes, as we know, from the Greek term "organon", which means "instrument" and therefore, intermediary. Getting organized or organizing ourselves means becoming the instrument, intermediary, passer, medium of a (more or less collective) action that will materialize and express itself through our contributions; contributions that will in turn materialize and express themselves through other beings (procedures, programs, protocols, titles, status, rules, spaces, temporalities, etc.).

To follow the process of organizing, as Bruno Latour [32] and Karl Weick [23, 24], each in his own way, invited us to do, therefore, amounts to accounting for the performances through which beings act as instruments or intermediaries to produce and express a body that may or may not articulate itself for another next first time, as Garfinkel [54] nicely puts it. This is the research question that the current material turn invites us to address. At the analytical level, this means that we can no longer merely identify the acts that people produce in interaction, but that we have to extend this agency - this capacity to act - to all the beings for which these same people act as spokespersons, intermediaries, media, and materializers.

Analysing the organizing properties of communication thus means that we can restitute, for instance, the properties of something as seemingly abstract and immaterial as an idea, that is, the way it materializes itself in a specific situation by the establishment of relations. In the rest of this paper, we propose to perform a detailed analysis of the pitch of an idea to illustrate our CCO position regarding this material turn. This pitch happened during a creative event called Museomix that took place in November 2014 at the Fine Arts Museum of a major North American city. Our analysis of this pitch will consist of detecting the moments where various beings (among them a stage, people, words, gestures, paintings, a wooden board, languages, expectations, etc.) became the instruments, media, passers, and materializers of the properties of a particular idea; an idea that, as we will see, came to exist and materialize more and more through these enactments.

\section{Method}

The analysis presented below is a (small) portion of a larger research project aimed at developing a communicative approach to organizational creativity. For this project, we observed and video shadowed [55] several activities aimed at collectively producing something innovative, such as brainstorming sessions and creative events, among them Museomix. Museomix is a yearly "creative event" that happens simultaneously in several museums around the world. For three days, 60 to 80 participants of various backgrounds (including art historians, graphic designers, software developers, 
entrepreneurs, etc.) meet in each participating museum to prototype new ways of experiencing the museum. As mentioned above, our study focused on the part of the event that took place in November 2014 at one of these museums, located in a major North American city.

For the three days of the event, we shadowed and videotaped the activities of two teams of participants (comprised of six members each), from the moment the teams were formed to the moment they presented their prototypes to the visitors of the museum. We also collected various documents that were used for organizing the event, including snapshots from Museomix's website and copies of the participants' handbook. Using the qualitative analysis software Transana, we then watched the videos, created a content $\log$ for each video file, and transcribed passages where the ideas developed by the participants seemed to undergo significant changes. We used Jefferson's transcript symbols [56] for the transcriptions.

We then analysed the transcribed passages. Our process of analysis can be described as follows: for each passage, we detected the relations through which an idea materialized itself by acquiring specific properties (starting with that of being an idea). In other words, we detected the configurations/relations through which various beings became the instruments, media, passers, and materializers of the properties of an idea. As already mentioned, these beings could have been of various natures (e.g. words, gestures, architectural elements, emotions, documents, rules, etc.). They could also have been more or less readily observable. Thus, while some beings were clearly identifiable at the moment they contributed to materializing an idea (e.g. the words "our idea is..."), others were contextual elements (e.g. requirements of the event) that contributed to the materialization of the idea at a distance by framing the participants' speeches and actions in a certain way.

As already mentioned, the analysis below focuses on the moment where one of the teams we followed "pitched" their idea in front of the other Museomix participants at the beginning of the event. To help our reader follow our data analysis, we divided the analytical section into two parts. In the first part, we present the requirements that participants were supposed to meet when pitching their ideas. These requirements were communicated to the participants in three main ways: through (a) Museomix's website, (b) the participants' handbook, and (c) instructions given by the organizers over the course of the event. In the second part, we analyse the pitch of the idea using elements from the transcript of the pitch and from the pitch requirements.

\section{The Pitch Requirements}

There were two main requirements that participants were supposed to meet when pitching their ideas: those that concern Museomix as a whole and those that concern the pitch specifically. While these various requirements can be regarded as particular materializations of Museomix (in the sense that they are elements through which Museomix expresses itself), this is not why we focus on them here.

We do so because they happen to materialize the properties that participants' ideas are supposed to acquire during Museomix. In other words, they are the properties that 
participants are invited to connect to one another while expressing their own ideas. In short, they are the peculiar form of existence that ideas have in Museomix before any participant expresses any idea. In the analysis below, we aim to identify not only these requirements, but also the various beings (organizers, texts, web pages, speeches, rooms, wooden signs, technologies, etc.) through which they materialize, that is, the particular configurations of relations through which these requirements happen to pass and express themselves. In that respect, we present the beings (organizers, texts, etc.) that materialize the beings (the requirements) that materialize the way participants' ideas should materialize (during the pitches).

\subsection{Requirements for Museomix as a Whole}

One of the key requirements was that participants had to develop creative ideas. This requirement can be derived from the way Museomix defines itself, whether it is on its website, in the participants' handbook, or in the organizers' speeches. For instance, one of the calls for participants available on Museomix's website reads: "Museomix is a lab for reinventing museums ... For three days, museums transform into sandboxes to create new experiences for the public" (our translation, museomix.org/appel-a-participants-2015, 2016-01-22). As we understand from this quote, Museomix (through its organizers and website) expects the participants to be "creative" in the usual sense of the term, that is, to "show an ability to make new things or think of new ideas" (MerriamWebster online dictionary).

As the same quote indicates, participants are supposed to use their creativity for one particular task - "reinventing museums". To help the participants figure out what this means, Museomix devised what they call six "grand challenges", which are supposed to materialize these particular expectations: "Showing the un-showable", "Renewing the visitor's experience", "Behaving in the museum", "The museum and the senses", "Copyrights in the museum", and "Business development at the museum". Museomix organizers do not tell the participants how they are supposed to respond to these challenges (this is precisely where they are supposed to be creative), but they ask them to indicate the one challenge to which they intend to respond. To this end, before pitching their ideas, participants had to write down their team name as well as "their challenge" on a wooden sign (see Fig. 2 below). If their idea was selected, the wooden sign would serve to identify the working space of their team for the rest of the event.

Another basic requirement of Museomix was to turn ideas into prototypes by the end of the event. As stated on the home page of its website, Museomix is a "three-day creative sprint in a museum" (our translation, www.technoculture.club/projets/Museomix, 2016-01-22). During the first half-day, participants were supposed to propose ideas and form teams around some of them. They then had two days to turn these ideas into some sort of digital-based prototypes. The remaining half-day was left for the visitors of the museum to come and test the prototypes. This basic program had been communicated to the participants through Museomix's website, the participants' handbook, and the introductory speeches the organizers gave at the beginning of the day. It was also reflected in one of the spaces available to the participants, the "techno room", which was packed with 
various technologies (e.g. laser-cutting machine, 3-D printer, touch screen, programming tools, etc.) that the participants were invited to use to build their prototypes.

\subsection{Requirements Specific to the Pitches}

The first two requirements that were specific to the pitches derived from the specifications of Museomix's team formation process. These specifications were detailed by the Museomix master of ceremonies at the beginning of the event and can be summarized as follows: there are seventy-two participants. Each participant falls into one of the seven following "profiles": "content expert", "communicator", "maker", "graphic designer", "user interaction expert", "[software] developer", and "improbable". Participants must form teams that include six members and at least five of these "profiles".

Note that the distribution of participants in teams is inseparable from the idea selection process, which took place in four steps: first, participants had to individually write down ideas on post-it notes that they stuck on large panels (each panel being dedicated to one "grand challenge"). Second, they were invited to talk to one another about the one idea they happened to like the most. If all went well, participants then started forming "team nuclei" around certain ideas. Third, each "team nucleus" pitched its idea in front of all the participants and mentioned the "profiles" they needed to complete their team. Fourth, participants had twenty minutes to negotiate and form teams that met the team formation criteria.

This elaborated team formation process had two consequences for the pitches: (a) When they pitched their ideas, teams were likely to be incomplete. A requirement of the pitch thus was to state the profiles that a team needed to be complete. (b) It was also likely that there would be more pitches than ideas that could be developed (as it turned out to be, twenty-two ideas were pitched and only twelve were developed). Another requirement of the pitch was thus to present an idea that was appealing enough to attract the participants that a team needed in order to be complete (and retain the ones it already had).

In addition to these, five other requirements more narrowly concerned the logistics of the pitches. Museomix's master of ceremonies introduced these last requirements a few minutes before the beginning of the pitches. As she explained, the teams that wanted to pitch their idea had to:

- Form a line on one side of the stage in the "plenary room",

- Step onto the stage when the master of ceremonies called them,

- Have a maximum of two speakers per team,

- Present their idea in no more than $45 \mathrm{~s}$,

- State the name of their team.

As shown in this analysis, to some extent, participants' ideas started to exist way before any participant expressed any idea. They materialized in (i.e. flowed or passed through) not only a series of requirements (some of them related to Museomix as a whole, others related to the pitches), but also the various beings that materialized (i.e. expressed) these requirements, namely: the participants' handbook, Museomix's website, speeches from the organizers (including a master of ceremony), wooden signs, the team formation process, the "techno-room", a set of technologies, large panels, post-its, a stage, etc. All 
these elements materialized properties ("having creative ideas", "making them appealing", "turning them into prototypes", "stating the profile that one needs", etc.) that the participants were invited to relate to one another during their pitches.

Of course, this does not mean that the participants were devoid of any agency. As we shall see now, relating properties to one's idea, especially if one aims to do this convincingly, takes a lot more than saying, for instance, "our idea is creative and appealing, we can turn it into a prototype, and we just need a developer". The art of relating predefined properties to ones' idea lies precisely in the various beings that one introduces between the predefined properties and ones' idea. This is what makes the idea hold together (that is, to materialize as an identifiable idea) and what makes it one's own.

\section{The Pitch of the "Secret Social Life of Artworks"}

It is 12:48 am on the first day of Museomix. One after another, twelve "team nuclei" have pitched their ideas. None of them, however, seemed to have sparked much enthusiasm among the audience (us included). People occasionally laughed at a joke made by one of the speakers, but most of the time they merely applauded at the end of the pitch. This is about to change.

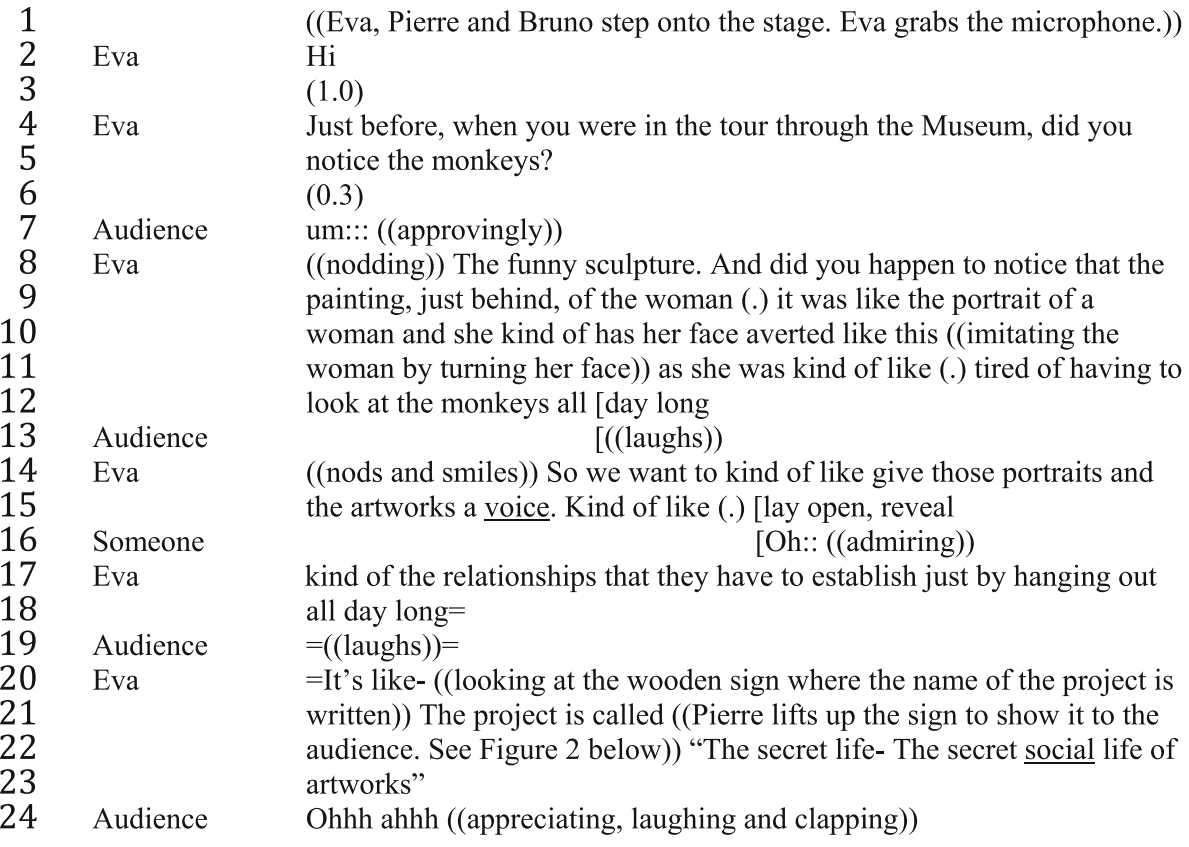




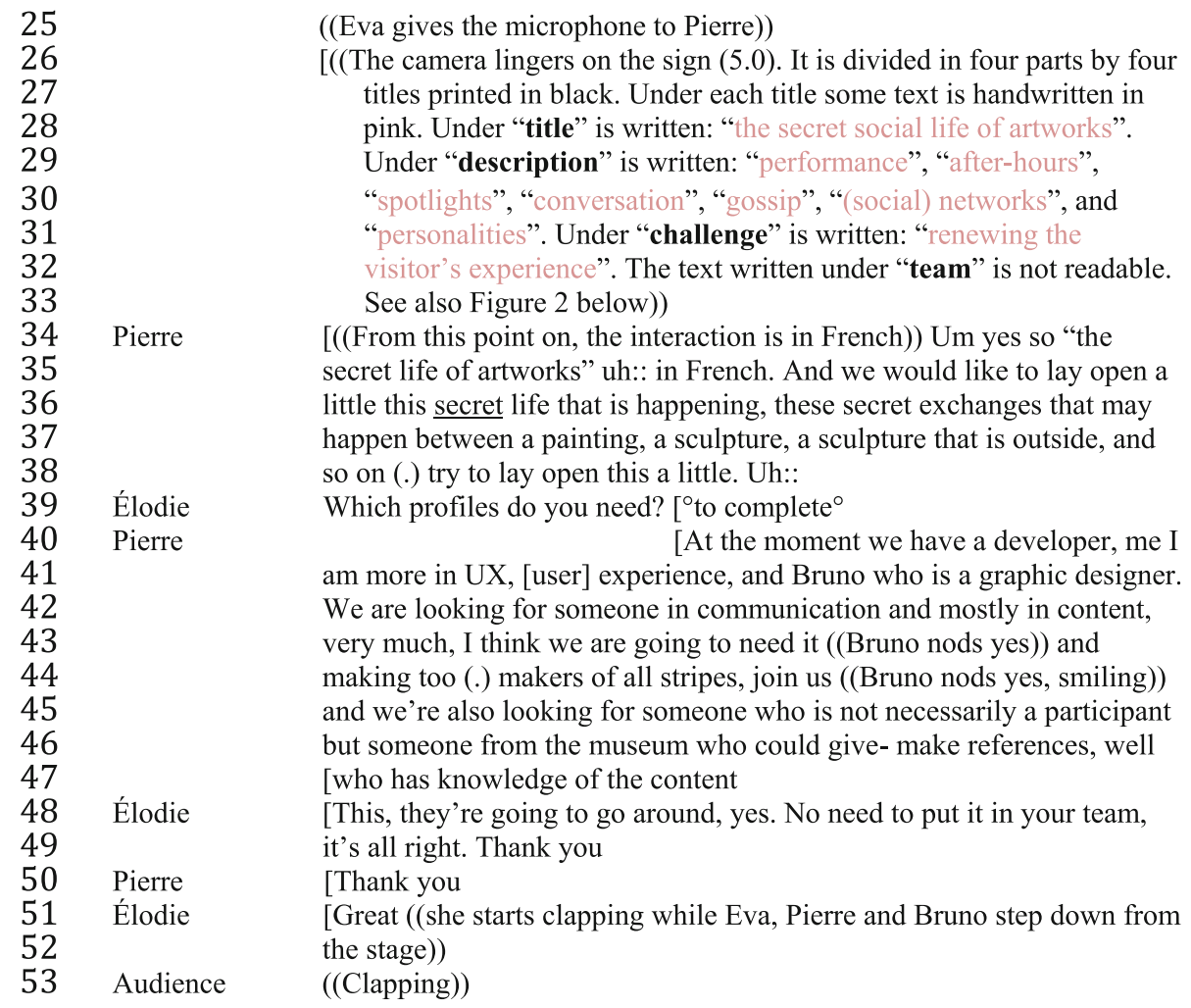

This excerpt can also be found here: https://youtu.be/GHmj0Zsqq-g.

At the beginning of this excerpt (1. 1-3), we see Eva, Pierre, and Bruno following the requirements that regulate the beginning of every pitch (during Museomix). When Élodie calls them, the three of them step onto the stage, Eva grabs the microphone to greet the audience. By doing this, they implicitly signal three things: (a) that they have an idea, (b) that they are about to present it, (c) that Eva will do the presentation. In other words, we could say that the idea - even if it has not been publicly expressed yet - has already materialized through three properties here: a team, a spokesperson, and a near future.

Eva then asks the audience a question - "Just before, when you were in the tour through the Museum, did you notice the monkeys?" (1. 4-5), to which the audience responds with an approving "um:::" (1. 7). Two comments can be made about this first exchange. First, while asking the audience if they noticed the monkeys, Eva says very little to identify them. She only says that they could have been noticed "during the tour through the museum" before calling them "the funny sculpture" (1. 8)), which is a way to stage their noticeable character as speaking for itself. Thus, when the audience confirms, through an approving murmur, that they did notice the monkeys, they also confirm their noticeable character, which somehow materializes itself in their reactions (the readers can judge for themselves by looking at Fig. 1 below). 


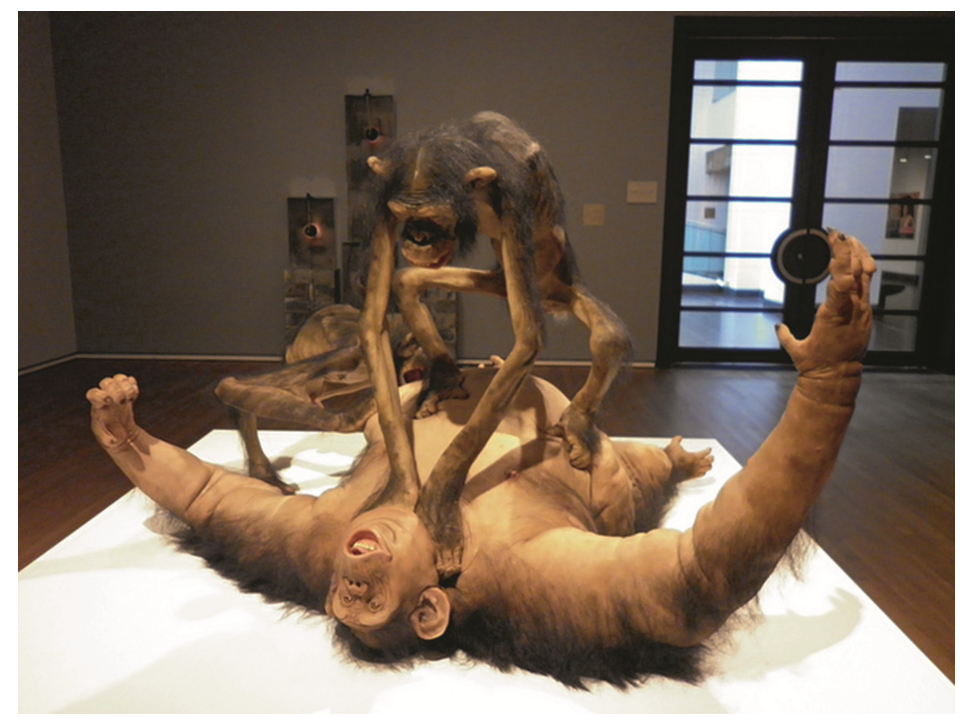

Fig. 1. "The monkeys" Eva refers to in her pitch, also known as "Old Enemy, New Victim" by Tony Matelli

Second, a basic requirement of the pitch script is, as we know, to present an "idea", in the sense of "a thought, plan, or suggestion about what to do" (Merriam-Webster online dictionary). The audience is thus invited to search for a connection between the monkeys' noticeable character and a "plan" or "project". Yet, there is nothing in what Eva says at this point that allows them to make this connection. There is thus a suspenseful or intriguing quality that becomes attached to the monkeys' noticeability. The audience is led to wonder: "what on earth is Eva trying to tell us with the monkeys?"

In short, at this point, the idea, which is about to be presented by Eva on behalf of her team, materializes through a new set of properties, namely the intriguing character of the monkeys' obvious and audience-confirmed noticeability.

Eva then asks the audience another question: "did you happen to notice that the painting, just behind, of the woman (.) it was like the portrait of a woman and she kind of has her face averted like this ((imitating the woman by turning her face)) as she was kind of like (.) tired of having to look at the monkeys all day long" (1.8-12). The audience responds by laughing (1.13). Four comments can be made about this part of the excerpt.

First, while presenting the woman as being tired of having to look at the monkeys, Eva carefully points out the elements that make this feeling plausible: (a) the painting of the woman is located "just behind" the monkeys (1. 9), (b) they are together "all day long" (1. 11-12), and (c) the woman has "her face averted" (1. 10). The presentation of these elements also changes the meaning of the monkeys' noticeable character, which now appears as a key element of the woman's feeling of weariness. Second, Eva discreetly indicates that the woman's weariness also has a fleeting nature. She asks the audience if they "happen[ed] to notice" the elements that support (or materialize) it (1. 8), thus suggesting that they may very well have not. She also presents these elements as being 
approximations ("[the woman] kind of has her face averted", 1. 9-10) or hypotheses ("as she was ... tired", 1. 11).

Third, while the woman's weariness (and everything that makes it plausible) certainly changes the meaning of the monkeys' noticeability, it still does not allow the audience to make a connection with an "idea" in the sense of a project or plan for action. In this respect, it only adds substance to the intriguing nature of what Eva is saying. Fourth, the audience's reaction (laughing) shows that the relation that Eva has established between the woman and the monkeys is funny, or at least funny enough to trigger these laughs. Thus, we could note that, at this point, the "idea" appears to materialize through the following properties (besides Eva and the team): the intriguing, funny, and fleeting nature of everything that makes the woman being tired of having to look at the monkeys plausible.

Eva then states: "So we want to kind of like give those portraits and the artworks a voice. Kind of like (.) lay open, reveal kind of the relationships that they have to establish just by hanging out all day long" (1. 14-18). The audience responds again by laughing (1. 19) while someone lets out an "oh::" of admiration (1. 16). Four comments can be made about this exchange.

First, Eva finally shows how the fact that the woman is tired of having to look at the monkeys can be connected to a project: (a) the woman's wariness is an example of "the relationships" that "those portraits and the artworks" (i.e. those of any museum) "have to establish just by hanging out all day long" (1. 14-18); (b) what Eva's team "want[s] to" do (1. 14) (i.e. their project) is to "give ... [these] artworks a voice" (1. 14-15) and "reveal [their] relationships" (1. 15-17). Of note, this connection dissolves the intriguing property that had built up so far. Second, the acts of "giv[ing] ... the artworks a voice" (1. 14-15) and "reveal[ing] their relationships" (1. 15-17) mark (or materialize) the transformative or creative nature of the project. Thanks to this project, what has been voiceless and hiding until now will be made audible and visible to everyone; what has been fleeting will become more enduring.

Third, the admiring "oh" that someone lets out in the audience (1. 16) marks (or materializes) the admirable nature of the project. This new property (being admirable) may be fragile in the sense that only one person seems to recognize it at this point, but it is clearly audible. Fourth, by laughing (1. 19), the audience materializes the funny nature of the project. So, at this point the idea presented by Eva on behalf of her team materializes through the following properties: it is the creative, funny, and somewhat admirable character of a project that is illustrated by the intriguing and fleeting nature of everything that makes the woman being tired of having to look at the monkeys plausible.

Eva then adds: "It's like- ((looking at the wooden sign where the name of the project is written)) the project is called ((Pierre lifts up the sign to show it to the audience)) 'The secret life- The secret social life of artworks"' (1. 22-23). The audience responds by letting out admiring "ohhh" and "ahhh" and by laughing and clapping (1.23). Five comments can be made about this exchange.

First, the project - and therefore the idea itself - now has a name. Second, this name echoes with several elements already presented by Eva. It recalls (i.e. expresses or materializes again) (a) that artworks develop relationships of their own (they have a "social life" (1. 22)); (b) that these relationships are easily missed by the visitors (they 
are "secret" (1. 22)); and (c) that the team's job is to make these relationships clearly audible and visible to the visitors. In other words, it is evocative of the plausible and fleeting nature of the relationships the project seeks to capture, and of the creative nature of the project itself.

Third, having the project name written on a wooden sign makes it more enduring or perennial. It amounts to delegating to the enduring qualities of the wooden sign the task of continuing to remind the participants of the plausible and fleeting nature of the relationships between the artworks and of the creative nature of the project. Fourth, the admiring "ohhh" and "ahhh" as well as the clapping and laughing (1.23) that come from everywhere in the audience at this point clearly confirm the admirable and funny character of the project. Fifth, to the extent that no other pitch has triggered such enthusiastic reaction in the audience before (and none will after), the audience's reaction at this point also marks the greater popularity of this project.

At this point, the idea presented by Eva on behalf of her team is made of such an intricate web of properties that it becomes difficult to summarize them. We could venture to say that it is made of (i.e. materialized through) the creative, admirable, funny, and popular character of a project that has an evocative and enduring title, and that is illustrated by the intriguing, fleeting, and plausible nature of the relationship between the woman and the monkeys.

The camera then lingers on the sign held by Pierre (1. 26-32, see also Fig. 2 below), which allows us to discover the other elements that are written there (that is, beside the project title). Several comments can be made about these elements.

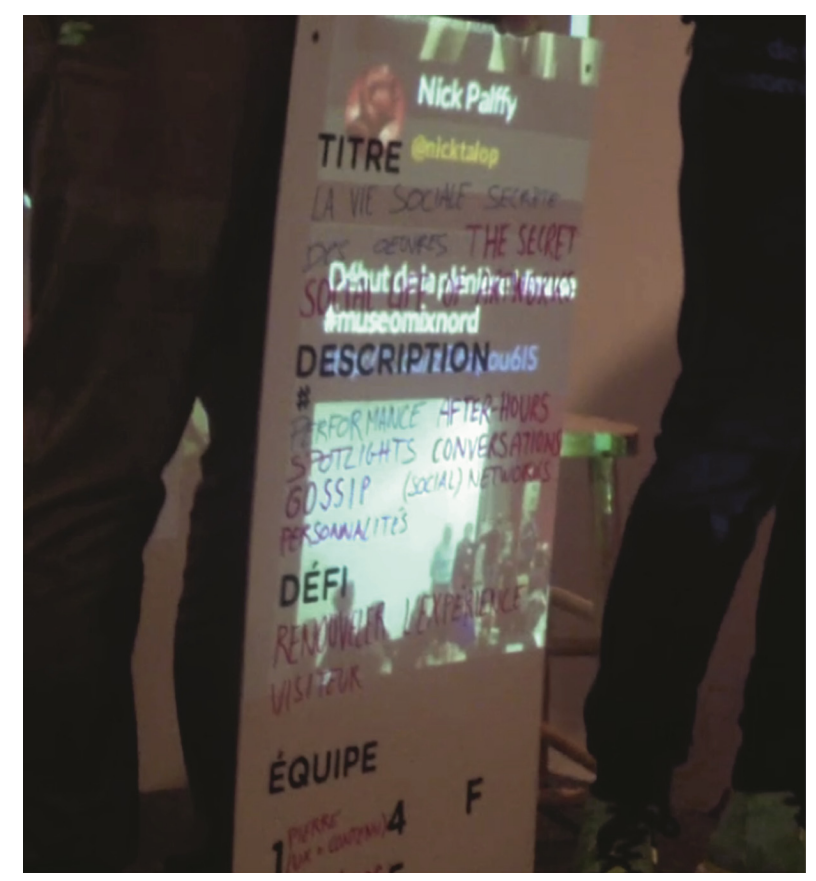

Fig. 2. Wooden sign held by Pierre during the pitch of the Secret Social Life of Artworks 
First, seven keywords are written under the label "description": "performance", "after-hours", "spotlights", "conversation", "gossip", "(social) networks", and "personalities". While it is difficult to know how exactly they relate to the project Eva just described, they seem to complement it by offering some leads as to how the project could be implemented. "Spotlights", for instance, seem to refer to technologies that could be used to render the artworks' relationships visible. In this respect, these keywords manifest (or materialize) the team's concern for the prototype they are supposed to build during the next two days.

Second, "renewing the visitor's experience" is written in the "challenge" section, which shows that the team has chosen to address this particular challenge among the six "grand challenges" proposed by Museomix (see above). Third, having the project "description" and the "challenge" it addresses written on a wooden sign makes them more enduring (that is, they materialize through more enduring beings). It allows them to keep "speaking" when no human (directly) speaks on their behalf, which is precisely what we see in the present situation.

These elements (i.e. the enduring quality of the team's concern for their prototype and their challenge) add to the web of properties through which the team's idea materializes.

Pierre then translates the project's title and objective in French (1. 33-37), which gives the team's idea yet another property - that of being partly expressed in French.

Élodie then asks Pierre: "which profiles do you need?" (1. 38). Pierre answers by telling those they already have ("a developer" (1. 39), someone in "[User] Experience", and a "graphic designer" (1. 39-40)) and then those they are looking for ("someone in communication [and] content" (1. 41), "makers" (1. 42), and "someone ... from the museum" (1.44)). Two comments can be made about this exchange.

First, we must recall that an idea is allowed to be developed in Museomix only if it is supported by a six-person team that includes at least five of the "profiles" specified by the organizers (see above). So, by telling which profiles they already have and those they are looking for, Pierre not only shows that their team is three members and two profiles away from being allowed to continue in Museomix - this is true for their idea too.

Second, while presenting the profiles they need, Pierre insists on one particular competence - "content". He says: "We are looking for someone in communication and mostly in content, very much, I think we are going to need it" (1. 40-43). This concern for "content" even leads him to free himself from the profile requirements and ask for "someone who is not necessarily a participant, but someone from the museum who ... has knowledge of the content" (1. 44-45). This insistence on "content" seems to be related to the fact that the project heavily relies on "the relationships that [artworks] establish just by hanging out all day long" (1. 17-18), which is part of the "content" of the museum. In other words, to some extent, it is the team's idea itself (i.e. its reliance on artworks' relationships) that dictates that they look for this particular competence.

Let us try to summarize the idea presented by Eva on behalf of her team one last time. This idea now materializes through the creative, funny, admirable, and popular character of a project that has an evocative and enduring title, an enduring preoccupation for a prototype and a challenge, that is partly translated in French, that is two 
profiles away from being allowed to continue in Museomix, that dictates a particular preoccupation for content, and that is illustrated by the intriguing, fleeting, and plausible nature of the relationship between the woman and the monkeys.

Finally, Élodie thanks Eva, Pierre, and Bruno (1. 47), Pierre thanks her back (1. 48), and the team steps down from the stage (1.49-50) while the audience is clapping (1.51). This last sequence of actions amounts to disconnecting the team's idea from the pitch situation, and therefore also from the means we had to follow it (at this point).

To conclude this analysis, it is noteworthy that the idea presented by Eva relates to many of the requirements we identified above. As we saw, this idea materializes notably through the following properties: it is presented by one spokesperson, speaking on stage, after being called by the master of ceremonies. It also appears to be not only creative but also admirable and popular (in other words, appealing). It shows a preoccupation for the prototype the team is supposed to build, for one of the challenges it is supposed to address ("renewing the visitor's experience"), as well as for the profiles it is supposed to include.

However, this idea also materializes (i.e. flows) through many other beings. First, it materializes through other properties: it is funny and intriguing, it has an evocative and enduring title, it is partly translated in French, it dictates a particular preoccupation for content, and it is illustrated by the fleeting and plausible nature of the relationship between the woman and the monkeys. In other words, all the properties we encountered in our analysis, whether they had been predefined by the organizers or not, contribute to giving substance to the idea presented by Eva.

Second, and perhaps more importantly, each of these properties materializes through specific configurations of beings. Consider for instance the fleeting nature of the relationship between the woman and the monkeys (a relationship that is supposed to illustrate the team's idea). This property cannot be said to inherently belong to the relationship between the woman and the monkeys, nor to the words that form the question "did you happen to notice...?", nor to the person who is asking it (Eva). However, when Eva asks this particular question about this particular relationship, the property "being fleeting" materializes. That is, it becomes a property of the relationship when Eva presents it as what relates the relationship, the words that forms the question she is asking, and the fact that she is asking it.

Therefore, the idea presented during this pitch does not materialize (i.e. flow) only through the properties that we highlighted in our analysis, but also through all the beings (words, gestures, intonations, artifacts, people) that materialize these properties when they happen to relate to one another in a certain way.

\section{Discussion}

So what can be learned from this analysis and to what extent does it allow us to go beyond the notions of entanglements and imbrications? First, we can note that at no point in our analyses did we have to choose between what belonged to the so-called material world and what belonged to the so-called social world. On the contrary, following the evolution of an idea consisted in identifying the various ways by which it 
materialized itself, whether (a) through the requirements about what this idea had to look like, requirements that precede the pitch itself or (b) through how this idea was presented to the audience when Eva and Pierre pitched it. In other words, we clearly saw that for an idea to exist, it has, by definition, to materialize itself through various beings that anticipated or embodied it.

Something as abstract as an idea can thus take multiple forms, which we first identified through the requirements that the organizers of Museomix communicated to the participants. These requirements specified what an idea had to look like, no matter what it came to be at the end, that is, they stipulated how it had to materialize itself; the properties/relations this idea had to establish in order to be selectable: (a) to be creative, (b) to reinvent museums, (c) to be translatable into prototypes by the end of the event, (d) to be defended by a team nucleus, and (e) to attract enough participants for its team to be complete. Although ideas had not been concretely and explicitly formulated yet, we saw that they had been materially anticipated by the Museomix device, whether through their website, the participants' handbook, or the instructions given by the organizers over the course of the event. In other words, even if they had not been defined yet, ideas started to materialize themselves through the discussions, discourses, and apparatuses that determined what properties they had to have.

While ideas and their expected properties had therefore been anticipated, we saw that the pitches themselves were the opportunity to present these ideas concretely, expecting that they would precisely meet the requirements that had been defined, presented, or discussed before. Our analysis allowed us to show how Eva cleverly crafted her speech to demonstrate that her team's idea indeed met or spoke to these requirements. How did she do that? Precisely by both presenting and reconstructing the properties of an idea that progressively materialized itself in front of her audience through the relations she established and revealed.

This idea, which, as we saw, had already been anticipated by the Museomix device, was able to acquire the following properties or characteristics: (a) intriguing, (b) creative, funny, and somewhat admirable, (c) illustrated (through the relationship, fictively reconstructed by Eva, between the "monkeys sculpture" and the "woman in the portrait"), (d) titled ("The Secret Social Life of Artworks"), (e) defined and summarized ("unveiling the (fictive) nature of the relationships between the museum artworks"). Each time, we saw that the properties/qualities/aspects/dimensions of this idea materialized themselves through something she said or embodied, but also through the beings she was staging in her talk: the monkeys sculpture, the woman in the portrait, the title she unveiled and presented through the wooden sign, etc.

In keeping with our ontological positioning, we see that we do not need to speak in terms of entanglement or imbrication between two separate worlds: the world of materiality and the world of sociality. What we have is, on the contrary, one (plural) world that always already presents itself through its material and social dimensions/aspects/ properties/qualities, that is, through its embodiments, which are always made of relations. We thus have a way to distinguish (ontologically and analytically) what we mean by social (the fact that something or someone is made of relations) and material (the fact that something or someone is made of other things), even if these aspects always appear together, but we also have a way to show that this distinction does not imply a separation 
between two worlds. Relationality and materiality should almost be seen - if we were to venture a metaphor, which always has its limitations - as the two faces of the same coin.

What we also hope we were able to show is that this analysis allows us to not only illustrate an epistemological/ontological argument, but also to teach something crucial about the relational/material dimensions of ideas. In other words, it says something about what could be called the communicative constitution of things we call ideas. Far from being reduced to the question of organizational ontology, we therefore see that the $\mathrm{CCO}$ perspective allows us to illustrate what communication scholars can say about topics that have been, until now, mainly reserved for psychologists and philosophers.

\section{References}

1. Orlikowski, W.J., Scott, S.V.: What happens when evaluation goes online? Exploring apparatuses of valuation in the travel sector. Organ. Sci. 25(3), 868-891 (2014)

2. Barad, K.: Meeting the Universe Halfway: Quantum Physics and the Entanglement of Matter and Meaning. Duke University Press, Durham and London (2007)

3. Orlikowski, W.J.: Sociomaterial practices: exploring technology at work. Organ. Stud. 28(9), 1435-1448 (2007)

4. Orlikowski, W.J., Scott, S.V.: Sociomateriality: challenging the separation of technology, work and organization. Acad. Manag. Ann. 2(1), 433-474 (2008)

5. Kautz, K., Jensen, T.B.: Sociomateriality at the royal court of IS: a Jester's monologue. Inf. Organ. 23, 15-27 (2013)

6. Cecez-Kecmanovic, D., Galliers, R., Henfridsson, O., Newell, S., Vidgen, R.: The sociomateriality of information systems: current status future directions. MIS Q. 38(3), 809830 (2014)

7. McPhee, R.D., Zaug, P.: The communicative constitution of organizations: a framework for explanation [electronic version]. Electron. J. Commun. 10, 1-6 (2000)

8. Putnam, L.L., Nicotera, A.M. (eds.): Building Theories of Organization: The Constitutive Role of Communication. Routledge, New York (2009)

9. Taylor, J.R., Van Every, E.J.: The Emergent Organization Communication as Site and Surface. Lawrence Erlbaum Associates, Mahwah (2000)

10. Schoeneborn, D., Blaschke, S., Cooren, F., McPhee, R.D., Seidl, D., Taylor, J.R.: The three schools of CCO thinking: interactive dialogue and systematic comparison. Manag. Commun. Q. 28(2), 285-316 (2014)

11. Cooren, F.: Communication theory at the center: ventriloquism and the communicative constitution of reality. J. Commun. 62, 1-20 (2012)

12. D'Adderio, L.: Artifacts at the centre of routines: performing the material turn in routines theory. J. Inst. Econ. 7(2), 197-230 (2011)

13. Leonardi, P., Barley, S.R.: Materiality and change: challenges to building better theory about technology and organizing. Inf. Organ. 18(3), 159-176 (2008)

14. Leonardi, P.M., Nardi, B., Kallinikos, J. (eds.): Materiality and Organizing: Social Interaction in a Technological World. Oxford University Press, Oxford (2012)

15. Butler, J.: Bodies that Matter: On the Discursive Limits of "Sex". Routledge, New York (1993)

16. Callon, M., Latour, B.: Unscrewing the big leviathan: how actors macro-structure reality and how sociologists help them to do so. In: Cicourel, A.V., Knorr-Cetina, K. (eds.) Advances in Social Theory and Methodology. Towards an Integration of Micro- and Macro-Sociologies, pp. 277-303. Routledge \& Kegan Paul, Boston (1981) 
17. Law, J. (ed.): A Sociology of Monsters: Essays on Power Technology and Domination. Routledge, London and New York (1991)

18. Deleuze, G., Guattari, F.: A Thousand Plateaus: Capitalism and Schizophrenia. University of Minnesota Press, Minneapolis (1980/1987)

19. Foucault, M.: Discipline and Punish: The Birth of the Prison. Vintage Books, New York (1975/1977). Translated by A. Sheridan

20. Jones, M.: A matter of life and death: exploring conceptualizations of sociomateriality in the context of critical care. MIS Q. 38(3), 895-925 (2014)

21. Leonardi, P.M.: When flexible routines meet flexible technologies: affordance constraint, and the imbrication of human and material agencies. MIS Q. 35(1), 147-176 (2011)

22. Leonardi, P.M.: Car Crashes Without Cars: Lessons about Simulation Technology and Organizational Change from Automotive Design. MIT Press, Cambridge (2012)

23. Weick, K.E.: The Social Psychology of Organizing. Random House, New York (1979)

24. Weick, K.E.: Sensemaking in Organizations. Sage, Thousand Oaks (1995)

25. Putnam, L.L., Pacanowsky, M.E.: Communication and Organizations: An Interpretive Approach. Sage, Newbury Park (1983)

26. Pickering, A.: The mangle of practice: agency and emergence in the sociology of science. Am. J. Sociol. 99, 559-589 (1993)

27. Faulkner, P., Runde, J.: On sociomateriality. In: Leonardi, P.M., Nardi, B.A., Kallinikos, J. (eds.) Materiality and Organizing: Social Interaction in a Technological World, pp. 49-66. Oxford University Press, Oxford (2012)

28. Mutch, A.: Sociomateriality: taking the wrong turning? Inf. Organ. 23(1), 28-40 (2013)

29. Leonardi, P.M.: Theoretical foundations for the study of sociomateriality. Inf. Organ. 23, 5976 (2013)

30. Kohn, E.: How Forests Think: Toward an Anthropology Beyond the Human. University of California Press, London (2013)

31. Latour, B.: Reassembling the Social: An Introduction to Actor-Network-Theory. Oxford University Press, Oxford (2005)

32. Latour, B.: An Inquiry into Modes of Existence: An Anthropology of the Moderns. Harvard University Press, Cambridge (2013)

33. Law, J.: After Method: Mess in Social Science Research. Routledge, London (2004)

34. Slife, B.D.: Taking practice seriously: toward a relational ontology. J. Theoret. Philos. Psychol. 24(2), 157-178 (2004)

35. Cooren, F.: In medias res: communication, existence and materiality. Commun. Res. Pract. 1(4), 307-321 (2015)

36. Martine, T., Cooren, F., Bénel, A., Zacklad, M.: What does really matter in technology adoption and use? A CCO approach. Manag. Commun. Q. 30(2), 164-187 (2016)

37. Cooren, F., Fairhurst, G., Huët, R.: Why matter always matters in organizational communication. In: Leonardi, P.M., Nardi, B.A., Kallinikos, J. (eds.) Materiality and Organizing: Social Interaction in a Technological World, pp. 296-314. Oxford University Press, Oxford (2012)

38. Ashcraft, K.L., Kuhn, T., Cooren, F.: Constitutional amendments: "materializing" organizational communication. Acad. Manag. Ann. 3(1), 1-64 (2009)

39. Bencherki, N., Cooren, F.: Having to be: the possessive constitution of organization. Hum. Relat. 64(12), 1579-1607 (2011)

40. Cooren, F.: The organizational world as a Plenum of agencies. In: Cooren, F., Taylor, J.R., Van Every, E.J. (eds.) Communication as Organizing: Empirical and Theoretical Explorations in the Dynamic of Text and Conversation, pp. 81-100. Lawrence Erlbaum, Mahwah (2006) 
41. Cooren, F.: Action and Agency in Dialogue: Passion, Incarnation, and Ventriloquism. John Benjamins, Amsterdam and Philadelphia (2010)

42. Derrida, J.: Specters of Marx: The State of the Debt, the Work of Mourning, and the New International. Routledge, New York (1994)

43. Robichaud, D., Cooren, F.: Organization and Organizing: Materiality, Agency and Discourse. Routledge, New York (2013)

44. Cooren, F., Kuhn, T., Cornelissen, J., Clark, T.: Communication, organizing and organization: an overview and introduction to the special issue. Organ. Stud. 32(9), 1149-1170 (2011)

45. Brummans, B.H.J.M., Cooren, F., Robichaud, D., Taylor, J.R.: Approaches in research on the communicative constitution of organizations. In: Putnam, L.L., Mumby, D.K. (eds.) Sage Handbook of Organizational Communication, pp. 173-194. Sage, Thousand Oaks (2014)

46. Cooren, F.: Organizational Discourse: Communication and Constitution. Polity, London (2015)

47. Taylor, J.R., Van Every, E.J.: The Situated Organization: Case Studies in the Pragmatics of Communication. Routledge, New York (2011)

48. Taylor, J.R., Van Every, E.J.: When Organization Fails: Why Authority Matters. Routledge, New York (2014)

49. Bakthin, M.M.: The Dialogic Imagination. University of Texas Press, Austin (1981)

50. Bakhtin, M.M.: Speech Genres and Other Late Essays. University of Texas Press, Austin (1986)

51. Cooren, F., Sandler, S.: Polyphony, Ventriloquism, and Constitution: in dialogue with Bakhtin. Commun. Theory 24(3), 225-244 (2014)

52. Fauré, B., Brummans, B.H.J.M., Giroux, H., Taylor, J.R.: The calculation of business, or the business of calculation? Accounting as organizing through everyday communication. Hum. Relat. 63(8), 1249-1273 (2010)

53. Peirce, C.S.: Peirce on Signs: Writings on Semiotic. University of North Carolina Press, Chapel Hill (1991)

54. Garfinkel, H.: Ethnomethodology's Program: Working Out Durkheim's Aphorism. Rowman \& Littlefield, Lanham (2002)

55. Vásquez, C., Brummans, B.H.J.M., Groleau, C.: Notes from the field: organizational shadowing as framing. Qual. Res. Organ. 7(2), 144-165 (2012)

56. Jefferson, G.: Glossary of transcript symbols with an introduction. In: Lerner, G.H. (ed.) Conversation Analysis: Studies from the First Generation, pp. 13-23. John Benjamins, Philadelphia (2004) 